structured medication reviews to optimise the impact of medicines, minimise the number of medication-related errors and reduce medicines waste. These are carried out in agreement with patient, nurse, family/carer and GP. The pharmacists also offer support to care home staff by reviewing, monitoring and improving medicines-related policies.

Results From January 2017 to January 2018, 574 medication reviews took place, leaving a total of 4997 medicines and 1787 suggested medication changes. Approximately $76 \%$ of these changes were agreed and actioned by patients' GPs, savings estimated using CCG costings of $£ 169,986.96$. A feedback survey to measure quality outcomes for patients, care homes and GPs is also underway.

Conclusions The introduction of pharmacists to the hospice's care home support team has offered considerable medicines knowledge and support to care home residents, relatives, hospice and care home staff, GPs and other stakeholders. The pharmacy team aspires to expand, develop even further into specialist clinical areas such as dementia and palliative care, and continue improving health outcomes and patient quality of life.

\section{P-207 SCOPING CARE HOMES SUPPORT... WHAT DOES GOOD LOOK LIKE?}

Kate Palmer, Sharon Hudson. Birmingham St Mary's Hospice, Birmingham, UK

\subsection{6/bmjspcare-2018-hospiceabs.232}

Without expansion of end of life care training for staff in care homes numbers of hospital deaths (of elderly, frail residents with dementia) will increase unsustainably (Bone et al, 2017). The challenges to education in care homes of high staff turnover, funding, time, attitudes, GP support and language and cultural differences (Marie Curie, 2017) impede this but there are established programmes, nationally, with evidence showing that, with high 'being present' facilitation supported by multi-layered learning, necessary change in this environment is achievable (Kinley, 2018). Whilst Birmingham St Mary's Hospice (BSMH) is a Regional Centre for Gold Standard Framework (GSF) Care Home Training and provides a substantial education programme, there is an urgent need to explore how to support local care homes better.

Aims Six months of discovery and design to produce an effective service model which facilitates on site education, embedding of sustainable systems and role modelling to local care home staff to improve their competence and confidence.

Methods Palliative Care CNS seconded for six months to:

- Map, scope and identify local and national evidence-based practice

- Design a model

- Test the model

- Collaborate with Birmingham University

- Audit and measure outcomes.

Initial results Preliminary interviews with 23 care homes show:

- Need for additional support (in particular health care assistants and on site)

- Examples of good practice (e.g. regular ANP and GP input)

- Uptake of education programme does not reflect the number of care homes

- Poor out of hours communication

- Poor communication from hospital
- Significant number of homes relying on more than two GP practices

- Some understanding of advance care planning but need to improve communication with families

- only four have embedded use of GSF.

Conclusions Prioritise completion of the Care Homes Project to produce a robust and flexible approach to facilitation. This project will build upon current research to produce innovative strategies in this arena.

\section{P-208 SUPPORTING END OF LIFE CARE IN A CARE HOME SETTING - A HOSPICE APPROACH}

Helen Reeves, Katie Taroni. St Giles Hospice, Whittington, Staffordshire

10.1136/bmjspcare-2018-hospiceabs.233

The national picture The NSF for Older People emphasised the need to provide the right care in the right place at the right time. Hospital is not necessarily the best place for older people, unless they are in need of acute medical or surgical intervention (Department of Health, 2001). Admissions are expensive (Department of Health, 2004) and often a frightening experience, particularly for those who are frail and vulnerable; people with advanced dementia are particularly vulnerable and frequently admitted to hospital, often unnecessarily (Department of Health, 2009).

In view of this St Giles Hospice are working with Virgin Care and SES CCG to support care homes in providing end of life care to their residents by providing expert support and implementation of key tools to help identify residents in their last 12 months of life.

Aims and objectives of the service

- Development of a 'Planning Ahead' register of frail patients at risk of admission or likely to be in the last 12 months of life using recognised and evidence based prognostic indicator(s)

- To ensure residents on this register have a care plan and advance care plan where appropriate

- To ensure valid DNACPR is in place for patients

- To ensure a valid RESPECT document is in place (where appropriate)

- To deliver reduction in the number of unplanned emergency admissions to hospital.

Outcomes and the future Currently St Giles Hospice are working with 25 homes providing weekly support sessions and review of the planning ahead register. There has been an increase in people achieving preferred place of death enabling $80 \%$ to die in their care home and of all admissions to hospital during this period only one was found to be avoidable. Quarterly reports/evaluations are collated with the aim to increase this service to all care homes within our area.

\section{P-209 COLLABORATION IN PRACTICE - BETTER OUTCOMES FOR MOST}

Kim Jones. Hospice of the Valleys, Ebbw Vale, UK

\subsection{6/bmjspcare-2018-hospiceabs.234}

Background The Care Home Palliative Education Programme is rolled out over 13 Care Homes and addresses: - palliative and end of life care, symptom control, communication skills, 
(Sage and Thyme), advance care planning and bereavement needs assessment.

Aim The aim of the education programme is to increase the knowledge, skills and confidence of the care staff which enables them to identify appropriate patients early and address the need for future planning as well as providing palliative and end of life care whilst supporting and involving families.

Method The education programmes are delivered in the care home and tailored to meet their specific needs. Working alongside care staff caring for our patients and families allows the hospice team and the staff to see the benefit of the education programme in practice and also to provide hands on 1: 1 education and support. This model of working also enables the team and staff to identify further educational opportunities.

Future planning with patients and families often takes place initially with the CNS until the staff feel confident. Using the wIPADS Framework has enabled staff to document and share these plans with the community MDT which has helped to reduce unnecessary admissions, investigations and treatments. Our patients often have multi-morbidities and parallel planning between specialities is essential in order to affirm life and prepare for death. The CNS and members of our family support team also provide carer support for families and on occasions for staff.

Results During the last 18 months the service has received approximately 180 referrals from our care home community of which 128 patients died. 126 patients died in the care home and two died in hospital. The enthusiastic care home staff supported by the hospice team and ongoing education programme has helped to reduce unnecessary admissions and ensures patient-centred care.

\section{P-210 TRUSTED ASSESSOR PILOT - MAKING SURE THAT PATIENTS ARE WHERE THEY NEED TO BE!}

Beverley Collins. ellenor, Kent, UK

\subsection{6/bmjspcare-2018-hospiceabs.235}

Background Many patients will unnecessarily wait too long for discharge from hospital resulting in a poor experience of the health/social care system, which may cause a reduction in their overall health outcomes (Emergency Care Improvement Programme, 2015). A pilot is being conducted to reduce numbers and waiting times of patients ready for discharge from hospital and facilitate their move back to their care home speedily, effectively and safely. A Trusted Assessor's (TA) role has been assigned and its role is to act as a central communications link, facilitator and trouble-shooter.

Aim The pilot aims to provide:

- Smoother transition between care providers thus improving the discharge of patients

- Potential reduction in bed days within an acute care setting following the timely discharge of patients involved with the pilot

- Evidence of how the TA model could work within care homes on a long term basis.

Methods Care home staff initiates referral to the TA about proposed hospital discharges. TA visits the hospital to assess patients admitted from a care home ensuring that all current end of life plans and clinical information are considered as discharge planning commences. TA liaises and confirms the patient's current condition can be managed by the care home and any equipment/medication is ordered prior to discharge. The TA is responsible for completing documentation for data review and audit trail.

Feedback Care home staff report communications have improved with the hospital because of intervention of the TA which keeps all parties in the discharge/admission loop. The hospital is monitoring potential reductions in bed days. Positive outcomes of pilot have helped build a new level of trust and co-operation between all parties.

Conclusion The impact of the pilot has been enhanced trust and working relationships for all stakeholders. Further explanation of the role is anticipated with recruitment of TA to cover more homes.

\section{P-211 THE MELODIC CARING PROJECT - INTRODUCING THE HEALING ELEMENTS OF MUSIC INTO ADULT HOSPICE CARE}

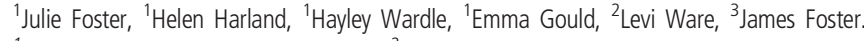
${ }^{1}$ Ashgate Hospicecare, Chesterfield, UK; ${ }^{2}$ Melodic Caring Project, Seattle, Washington, USA; ${ }^{3}$ Chesterfield College, Chesterfield, UK

10.1136/bmjspcare-2018-hospiceabs.236

Background The Melodic Caring Project (MCP) was created in 2010 when founder Levi Ware set up a live stream from a music concert for a local girl receiving chemotherapy. Staff at Chesterfield College, witnessed MCP and developed a learning opportunity in partnership with MCP for Media students to stream live music. The college contacted Ashgate Hospicecare to develop this project further for adult patients with life-limiting illnesses.

Aims

- To bridge the gap between music and patients by streaming live concerts to Ashgate Hospicecare

- To embrace the therapeutic properties of music to alleviate pain, anxiety and promote patient wellbeing (Harvard Men's Health Watch, 2011; Standley, 1986)

- To provide college students with regular broadcasting work experience.

Methods Chesterfield College arrange Artist/venue participation and share with Ashgate Hospicecare who identify patients to take part/have their names 'shouted out' on stage. Chesterfield College team attend and live stream the concert to Ashgate Hospicecare via a laptop. Patient/family feedback recorded by Ashgate communications team with consent.

Results

- Since December 2017, four live events have been successfully streamed to eight patients

- Patients and relatives report the benefit of this initiative bringing a feeling of normality back to their lives

- Nurses report a reduction in one patient's pain relief requirements leading up to and during the concert and another patient delayed her discharge home in order to take part.

Conclusion MCP provides a unique personalised experience for patients and their families and evaluates very well through patient/family feedback

Innovation Through support from MCP and Chesterfield College, Ashgate Hospicecare have successfully provided MCP 